\title{
EL PAYT⿱AN R. ISAAC DE CASTELLÓN
}

\author{
C. DEL VALLE \\ CSIC. Madrid
}

En el bello códice de la British Library, el manuscrito Add. 14761, que contiene la celebérrima haggadâ de Barcelona, códice del XIV ', aparece un poema, en verso medido, no puntuado, atribuido a R. Isaac de Castellón ${ }^{2}$. L. Zunz lo mencionó en su Literaturgeschichte der synagogalen Poesie, aunque erró en la interpretación del nombre gentilicio del poeta, leyendo Isaac de Capestan ${ }^{3}$. I. Davidson registró el primer estico del verso inicial en su Thesaurus, leyendo también erradamente el gentilicio - Cabeston- ${ }^{4}$.

El poema, a no ser que estemos errados en nuestra información, no ha sido todavía publicado hasta el día de hoy. Pero tiene interés, no sólo para conocer una parte de la producción literaria de Isaac de Castellón, sino por los méritos intrínsecos de la composición, sobre todo en el arte métrico.

Del autor del poema, Isaac de Castellón, apenas tenemos información. Omiten toda referencia a su persona u obra los clásicos bibliógrafos judíos, como M. Steinschneider s, J. Fürst ' ${ }^{6}, \mathrm{Ch}$. B. Friedberg ', así como los antiguos I. Bartolocci ${ }^{8}$ y J. Ch. Wolf ${ }^{9}$.

1 G. Margoliouth, Catalogue of the Hebrew and Samaritan Manuscripts in the British Museum, London 1905, II, págs. 197-198, $\mathrm{n}^{\circ}$ 605. Una reproducción facsímil de este códice está actualmente en marcha.

2 אחבח לרי יצחק דקשטיון ז"יל (Ms. Add 14761, fol. 149b).

${ }^{3}$ Berlin 1865, pág. 558.

${ }^{4}$ Thesaurus of Mediaeval Hebrew Poetry, New York 1924, yôd, pág. 287.

${ }^{5}$ Catalogus Librorum Hebraeorum in Bibliotheca Bodleiana, Berlin 1931.

${ }^{6}$ Bibliotheca Judaica, Leipzig 1849.

${ }^{7}$ Bet Eked Sepharim, Tel Aviv 1952.

${ }^{8}$ Bibliotheca Magna Rabbinica, Romae 1683.

9 Bibliotheca Hebraea, Hamburgi-Lipsiae 1727. Tampoco se incluye su nombre en la lista de paytanim que incluye Abraham David en la Encyclopaedia Judaica, vol. 13, Jerusalem 1971, col. 581 . 
Lamentablemente, tampoco existe hasta el momento, pormenorizada, una historia de la judería de Castellón, con atención tanto al dato socio-histórico como al puramente cultural e histórico, donde se pueda recoger información fidedigna sobre autores judíos locales. El trabajo más notable al respecto es el de José Ramón Magdalena que reunió una serie de notas documentales, de carácter socio-económico, sobre la judería de Castellón en la Baja Edad Media ${ }^{10}$. Las noticias, dispersas y desarboladas, de Juan A. Balbás sobre los judíos de Castellón pertenecen también al período tardío (siglos XIV y XV) ".

Dada la edad del manuscrito donde aparece el poema (siglo XIV) y dadas las características métricas del mismo, con una técnica en la formación de la estrofa muy avanzada, hay que suponer que el autor vivió en el siglo XIII, posiblemente dentro ya del reino cristiano ${ }^{12}$. De ahí que resulte muy probable que $R$. Isaac de Castellón, autor del piyyût o poema litúrgico que aquí editamos, sea el mismo Bissach Castellon - R. Isaac de Castellón, en la transcripción hebrea - al que se refiere un documento de Pedro IV de 26 de julio de 1373. El rey convoca a los rabinos Nissim y Azday Cresques, de Barcelona, para que decidan, según el derecho rabínico, una difícil cuestión que ha surgido con los matrimonios de descendientes de R. Isaac de Castellón. Unos 70 años antes, se celebraron matrimonios con los hijos de $\mathbf{R}$. Isaac de Castellón y con los de un hermano suyo $\mathrm{y}$ entre parientes suyos, que fueron considerados lícitos y válidos por R. Yoná de Gerona y R. Salomón (ben Adret). Sin embargo, desde 50 años a esta parte, hay un grupo de gentes que consideran tales matrimonios ilícitos. Las consecuencias inquietantes que de ello se seguirían, si esta última acusación fuera verdadera, serían alarmantes

attenta copiosa multitudine illorum ex predictis, qui se matrimoniali federe conjunxerunt quique fuerunt et sunt de bonis et melioribus judeis dicti nostri regni.

\footnotetext{
${ }^{10}$ La aljama hebrea de Castellón de la Plana en la Baja Edad Media, Castellón de la Plana 1978.

$"$ El libro de la provincia de Castellón, Castellón 1892, págs. 137-149.

12 Castellón pasó al poder de los reyes de Aragón en 1233. Cf. J. R. Magdalena, op. cit., pág. 46.
} 
Por eso el rey les ordena

quid secundum jus ebraycum de premissis habet essentiam veritatis ${ }^{13}$.

El piyyût de $\mathrm{R}$. Isaac es de carácter místico y señala la inmensidad de Dios, omnímodo presente, en el empíreo y en el abismo, pero oculto e infranqueable cuando el hombre a él se allega. Las obras de sus manos, los cielos, testifican a Dios, pero es en el interior del corazón o de la mente donde el hombre puede mejor darse cita con él. Es nada lo que el hombre sabe de los misterios de Dios, que el sabio ha de celar como el propio Dios cela sus misterios hasta que no llega el término fijado. Pero, en definitiva, ¿qué hay de extraño en que el hombre no entienda ni comprenda la esencia divina cuando él mismo ignora el fundamento de su propio ser? El poeta acaba con una invitación a proclamar la unidad divina y a alabar a Dios.

Según reza la rúbrica del mahzốr barcelonés, el poema estaba concebido como una 'ahabâ, el piyyụt que se insiere en las bendiciones del yôser, delante de "el que escoge a Israel con amor", piyyût, generalmente, como en el caso presente, de forma estrófica ${ }^{14}$.

La estructura puramente formal del poema es llamativa. Son cuatro las estrofas, integradas cada una por dos versos trípticos y otros dos dípticos. La rima en los dos versos largos es alternante, según el tipo $a b a, b a b$, y es diferente en todas las estrofas. Sin embargo, en los dos versos menores, de dos esticos, la rima final es diferente en cada uno de los versos, pero igual en todas las estrofas: $a b, a b, a b, a b$. El último verso del díptico siempre se dobla.

En los versos mayores, cada estico está compuesto por el conjunto de $2 t\left(e_{n} u^{\top} \hat{o} t\right), 1 y($ ated $), 2 t$. y $1 y$. alternando con $2 t$., $1 y$., $2 t$., $1 y$. y $1 t$.

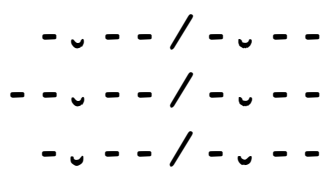

${ }^{13}$ Documento en el Archivo de la Corona de Aragón, Reg. 1239, fol. 72v, reproducido por F. BAER, Die Juden im christlichen Spanien, Berlin 1929, I, n 309, págs. 450-451. En el mismo año y sobre el mismo asunto, el rey se dirigió a otros rabinos de las comunidades de Tortosa, Gerona, Cervera, Perpiñán y Peralada; cf. F. BAER, ibid., págs. 451-452.

14 C. DEL VAlle, El diván poético de Dunash ben Labrat, Madrid 1988, pág. 151. 
Haciendo una lectura de los pies, serían: mitpa'alim, mitpacalim; mitpacalim, mitpacalanim. En los versos dípticos, los dos esticos del primer verso y el primero del segundo: $2 t$., 1 y. y $2 t$. (mitpacalim, nif al o nif'al, méfo'alim ${ }^{15}$. Por tanto, serían, básicamente, una variante del metro harûz ${ }^{16}$.

\section{Texto del poema}

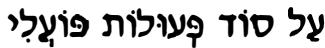

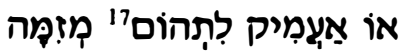





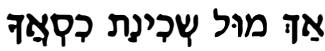

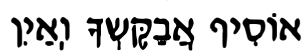

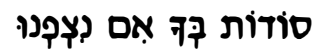

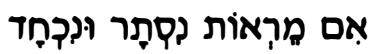





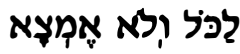

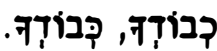

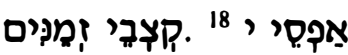

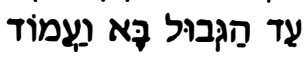

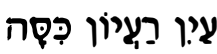

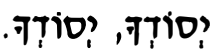

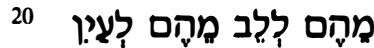

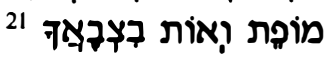

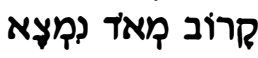

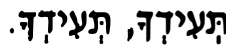

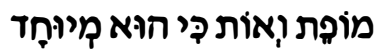

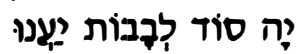

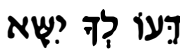

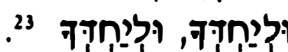





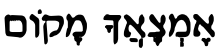

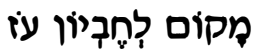

5

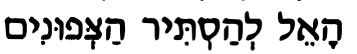

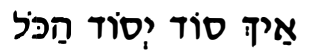

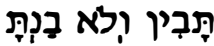

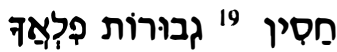

10

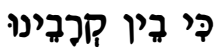

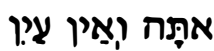

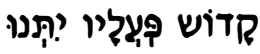

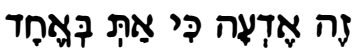

15

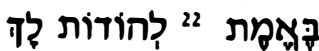

\section{0} 15

is Establezco la diferenciación de los pies respondiendo a una expectativa académica, aunque soy consciente de que este hábito académico es inútil y superfluo. Los pies sólo tendrían sentido en el verso, si, aparte de la alternancia vocálica cuantitativa, señalaran también la posición del acento en el verso, siendo obligado, en tal caso, usar la terminología primitiva árabe para designar los pies y no la hebrea introducida por Saadia Ibn Danan. Véase mi "Visión diacrónica de la métrica hebrea» en la obra antes citada, págs. 113-147.

${ }^{16}$ En la misma obra indico la grave dificultad para reducir algunos de los metros hebreos a los árabes y la pura convencionalidad en su descripción y la diferente terminología con que pueden ser designados, cf. ibid., págs. 113 ss.

17 Por exigencia métrica ha de pronunciarse lit-hôm, y no li-țěhôm, convirtiéndose el sěwa' móvil en quiescente.

18 Véase la interpretación del $y \delta \underline{d}$ en el comentario del poema.

19 hasin, y no hásin, por imposición métrica. Al final del estico he corregido el manuscrito leyendo $p l^{\prime} k$ en vez de $p^{\prime} l k$.

${ }^{20} l e x-c a-y i n$, con diéresis por imposición métrica.

${ }^{21} B i-s e b a^{2} a-\underline{k} a$; por imposición métrica: bis-ba-'a-kia.

${ }^{22}$ be'-met, por imposición métrica.

${ }^{23}$ ul-yahl-dé-ka. 


\section{Traducción castellana}

Sabe mi corazón que nada

sabe. Ésta es mi parte en la sabiduría ${ }^{24}$

de los misterios de las obras de mi Hacedor,

¡el que cuelga de la nada los pilares [de la tierra] ${ }^{25}$.

Porque, si subiere a los lomos de los cielos ${ }^{26}$

o me hundiere en los abismos del pensamiento ${ }^{27}$

te hallo a ti, lugar

del universo, pero no atino ${ }^{28}$

el espacio donde se oculta el poder de tu gloria, de tu gloria ${ }^{29}$

Oh tú que avizoras para entender el secreto ${ }^{30}$ de los confines de los límites de los tiempos ${ }^{31}$

\footnotetext{
${ }^{24}$ Bĕll negación. "Sabe mi corazón que no sabe».

25 "Pender o colgar de la nada", expresión para significar la creación, a partir de Jb 26,7: “cuelga la tierra de la nada». "Porque la tierra está colgando en medio de la esfera" (A. IBN 'EZRA, Com. a Job 26,7, cf. J. BEN HAyYIM (ed.), Biblia Rabbinica, A Reprint of the 1525 Venice Edition, Jerusalem 1972, ad loc.). מצוקי ארץ (1 Sam 2,8), "columnas de la tierra" (D. QIMHi, Sefer, ha-Šorasłan, cf. J. H. R. Biesenthal - F. LEBRECHT [eds.], Berolini 1847 [reimpr. Jerusalem 1967], s. v. swq). Véase Sal 75,4.

${ }^{26}$ El metro del poema exige leer $t e x h$ y no til. $h$. Těh significa, en rigor, el punto medio de la eclíptica Y. KeNAANI, Osar ha-lašon ha-'ivrit, Giwatayim 1989, ad loc. y significa aquí la máxima altura, en contraste con la máxima bajura o abismo que se enuncia en el estico inmediato siguiente.

${ }^{27}$ Ciertamente el poeta rememora las palabras del salmista: "Si a los cielos subiere..." (Sal 139,8).

${ }^{28}$ Dios como lugar del universo es un tópico muy frecuente en los escritos de Ibn Gabirol. «Ellos no te contienen, pero tú los contienes, porque tú eres tu lugar y tú su lugar" (N. Allony, "Mi-širat Rašbag u-lěsônô", HUCA 47 [1976] 1-104, 60 [heb.]). Véase F. DE CASTro (trad.), Shelomó Ibn Gabirol. La fuente de la vida, Barcelona 1987, pág. 253. "Nuestros doctores llamaron al nombre de Dios maqóm [lugar], porque él es el lugar del universo y no el universo su lugar» (D. QıMḤı, op. cit., s.v. 'wn).

29 חביון עr es una alusión a Hab 3,4.

${ }^{30} \mathrm{El}$ poeta se refiere ahora al hombre, o a él mismo. El hombre, como desde una atalaya, otea el horizonte, escudriña el universo, en una acción de calado en el misterio de Dios.

${ }^{31} \mathrm{La}$ interpretación de este estico es ciertamente ardua. No hay duda de que entre 'afsê y qisb $\hat{e}$ hay un $y \hat{o} \underline{d}$ intermedio, separado de uno y otro término. En el manuscrito, que he comprobado dos y tres veces, el $y \delta \underline{d}$ aparece claro. Hay que exluir que el $y \delta \underline{d}$ sea prefijo verbal, incompatible con la forma constructa precedente y el sufijo nominal - $l$. La única razón plausible es que el poeta recurriera aquí a una licencia poética. Por necesidad métrica tuvo que movilizar el $y \delta \underline{d}$ final de 'afsê. Véase mi obra, El diván, págs. 277, 469, 186. Aun así, para que la lectura del estico se ajuste al metro, es necesario movilizar el ‘ěwa' quiescente de qisbể [qi-sa-bể].
} 
oculta [estas] realidades ${ }^{32}$, porque es gloria de Dios emboscar los secretos hasta que al término su arribo llega.

¿Qué te va a ti el pasado y el futuro? ${ }^{33}$

¡Cómo el secreto del fundamento del universo

-que el ojo de la razón cubre-

entenderás, si no alcanzas tu fundamento,

tu fundamento!

Potentísimas son tus maravillas, al entendimiento y a los ojos ${ }^{34}$.

Mas frente a la Presencia de tu trono

los ojos y el corazón languidecen.

Las pruebas y señales están en tus cielos ${ }^{35}$.

Te buscaré todavía más y dónde

sino en nuestro interior,

donde tú estás más cercano.

¡Ningún ojo dará testimonio de ti, dará testimonio de ti! ${ }^{36}$.

¡Tus obras, oh santo, proporcionan

argumento y prueba de que eres único! ${ }^{37}$.

¡Misterios hay en ti, aunque ocultos!

Esto sé: ¡Eres único!

Yah, [tu] misterio los corazones cantan, aunque oculto y escondido a los ojos ${ }^{38}$.

Por eso el corazón del sabio

su saber a ti expresa,

${ }^{32} \mathrm{El}$ celar los misterios divinos es un tópico que recurre frecuentemente en la poesía hebrea. Recordemos, por ejemplo, un poema de Ibn Gabirol: «Éste es tu nombre, que siempre se ha de celar... (D. YARDEN, Širê ha-qodes lé-rabl Šelomoh 'ibn Gabirôl, Jerusalem 1971-1973, pág. 18).

33 Jer 7,24 “¿Por qué tienes que escudriñar las profundidades de la divinidad?».

${ }^{34} \mathrm{Me}$-hem, con valor partitivo. Leb, 'corazón, inteligencia'. Véase D. QIMHI, op. cit., s. v. labb.

${ }^{35}$ Saba', 'ejército, cielos' (Y. KenAANI, op. cit., s. v. sb').

$36 \mathrm{Jb} 29,11$.

${ }^{37}$ Aunque el autor se expresa en tercera persona, la referencia a la segunda es palmaria, como puede comprobarse en el estico tercero del mismo verso y tal como es práctica corriente en los poetas hebreos. Véase "Yosef Ibn Abitur" en H. BrodYM. Wiener, Anthologia Hebraica, Leipzig 1922, vi 10, 9 y 22; D. PaGIS (ed.), The Poems of Levi al Tabban, Jerusalem 1964, pág. 105, n. 38.

${ }^{38} \mathrm{El}$ metro exige la lectura me-rệt $\underline{t}$ : el $\min$ con valor negativo. 
ciertamente, para alabarte

y proclamar tu unidad,

proclamar tu unidad ${ }^{39}$.

\section{RESUMEN}

Edición y traducción castellana de un piyyût de R. Isaac de Castellón (s. XIII), según el Ms. Add. 14.761 de la British Library. El poema suministra una base para conocer mejor a $\mathrm{R}$. Isaac de Castellón y sus técnicas poéticas.

\section{SUMMARY}

Edition and Spanish translation of a piyyût of $R$. Isaac de Castellón (13th century), according to the Ms. Add. 14.761 of the British Library. The poem allows us to know better the poetical technics and the mentality of $R$. Isaac de Castellón.

${ }^{39}$ Yahed, 'proclamar la unidad' (de Dios). Véase C. DEL VALlE, op. cit., págs. 178 y 490). 